\title{
Towards a Knowledge Typology for New Product Development Engineering Processes
}

\author{
B.Donnellan ${ }^{1}$, B. Fitzgerald ${ }^{2}$ \\ ${ }^{1}$ Centre for Innovation and Structural Change, National University of Ireland, Galway, Ireland \\ ${ }^{2}$ Department of Computer Science and Information Systems, University of Limerick, Ireland
}

\begin{abstract}
In today's competitive and turbulent environment companies engaged in New Product Development (NPD) need to have a sophisticated understanding of the types of knowledge critical to the each phase of the NPD process. These types of knowledge are used in so-called "stage-gate" NPD processes. This paper will describe a typical NPD stage-gate process and indicate the critical knowledge types needed at the different stages. The identification of the critical knowledge used at each stage was done by combining knowledge of the literature and practical experience of running NPD processes in an industrial setting. The different types of knowledge required at different stages of the development process will be described and elaborated on. When providing knowledge management systems to support the NPD process, one needs to consider providing a system that can cater for knowledge that may take different forms. This research contributes to our understanding of the nature of those knowledge forms.
\end{abstract}

Keywords-Knowledge Management Systems, New Product Development, Knowledge Typology.

\section{INTRODUCTION}

"Knowledge work" has four defining characteristics (i) the work is based on a Body of Knowledge, (ii) the work entails working on representations of the objects of work (data),

(iii) the work requires a deep theoretical understanding of the objects of work, and

(iv) the work produces results, which entail knowledge as their essential ingredient [1]

People engaged in NPD are doing knowledge work. Management of that knowledge is seen as a key factor in the creation of sustainable competitive advantage for companies engaged in NPD. Porter points out that current strategic management thinking on the sources of competitive advantage sees the ability to learn and adapt as being the only sustainable source of competitive advantage for companies operating in today's economic environment. He goes on to identify the key strategic imperative for NPD organizations as the drive to "strengthen innovative capacity" [2]. This viewpoint suggests a strategic perspective centered on developing core competencies and understanding the competitive advantage of "know-how" [3]. This perspective is shared by researchers whose resource-based view of competitive strategy sees long term benefits for a firm in so far as knowledge management initiatives direct attention towards the most important and productive resources deployed by firms and focus minds on the role of knowledge within the firm [4]. In particular, there is now a lot of focus on ways that organizations have designed and implemented their business processes with a view to leveraging the knowledge inherent in those processes.

One such process used by companies engaged in NPD is the so-called "stage-gate" process [5]. A stagegate process is a conceptual and operational road map for moving a new product project from idea to launch. What differentiates stage-gate processes from other NPD processes is that decision-making events follow each stage. Gates are meetings where the project undergoes a thorough examination and after which management decides whether to incur more expense in the project or not. NPD teams complete a prescribed set of related cross-functional tasks in each stage before getting approval to proceed to the next stage of product development. The gates represent control points where teams' plans are repeatedly re-assessed in the light of the additional information that emerges during the life-cycle of the project. Different phases of the NPD process may have different decision-making requirements [6], [7], [8].

A variant of the stage-gate process is in use in a multi-national Integrated Circuit manufacturer. The company will be referred to as company "A". There are different types of knowledge required at different stages of the development process. This research is concerned with how the critical knowledge types needed at the different stages in a typical NPD stage-gate process in company " $A$ " were identified and addressed. A table showing the structure of the paper is shown in Table 1.

\section{TABLE I: PAPER STRUCTURE}

\begin{tabular}{ll}
\hline I & $\begin{array}{l}\text { Introduction: Motivation and background to the } \\
\text { research study }\end{array}$ \\
\hline II & $\begin{array}{l}\text { Research Method: Rationale for choosing Action } \\
\text { Research and description of the research method. }\end{array}$ \\
\hline III & $\begin{array}{l}\text { Knowledge Typologies: Overview of the literature } \\
\text { and identification of two sub themes - Generic and }\end{array}$ \\
& Practice-Based Knowledge Typologies. \\
\hline IV & $\begin{array}{l}\text { A New Knowledge Typology For NPD: } \\
\text { Description of a new Knowledge Typology for }\end{array}$ \\
& NPD based on literature synthesis and practice. \\
\hline V & $\begin{array}{l}\text { Conclusions: Summary of the work to-date and } \\
\text { identification of contributions to knowledge. }\end{array}$ \\
\hline
\end{tabular}




\section{RESEARCH METHOD}

Qualitative research using an interpretative paradigm is especially appropriate for research in knowledgerelated aspects of NPD because a central concern of the research is the uncovering of facts in the everyday life of the individuals in the community under study. Through the uncovering by these facts it is easier to understand the needs which affect knowledge-creating behavior. In this case, the sharing of knowledge to support NPD processes is perceived as a social process and the research sets out to understand it in practice from the participants' perspectives. This, therefore, implies the use of an interpretative research paradigm in which the world as seen as being socially constructed and subjective, and can therefore only be interpreted. The organization under study is a world leader in the design, manufacture, and marketing of integrated circuits (ICs) used in signal processing applications. Founded in 1965, company "A" employs 8,500 people worldwide.

The general approach adopted for this research was to

- Act as member of the team (within the organization) that identified the primary problems that gave rise to the organizations desire to change.

- Work with stakeholders to specify organizational actions to address those primary problems.

- Collaborate with members of the organization to implement the planned action.

- Evaluate the outcome.

- Reflect on the new knowledge gained as a result of the research.

This approach is based on an Action Research (AR) model for qualitative research. Lewin originally described the action research cycle as having four basic steps: diagnosing, planning, acting and evaluating [9]. He saw the process as a "spiral of steps, each of which is composed of a circle of planning, action and fact-finding about the result of the action" (p.206). The AR model applied in this research is similar to that described in [10] and sees the research process as a five phase cyclical process containing the following discrete steps: diagnosis, action planning, action taking, evaluation and leaming.

The AR method recognizes that a research project should result in two outcomes, namely an action outcome and a research outcome. Taking each in turn: firstly the action outcome is the practical learning in the research situation. Thus, a very important aspect of the research is the extent to which the organization benefits in addressing its original problem. This serves to ensure the research output is relevant and consumable to practice. Secondly the research outcome is very much concerned with the implications for the advancement of theoretical knowledge resulting from the project.

\section{KNOWLEDGE TYPOLOGIES}

The challenge to deconstruct knowledge into different types or classes is one that researchers have been grappling with for many years. These typologies can be seen as falling into two categories :- (i) generic typologies that attempt to describe a generic set of knowledge types applicable to many situations and (ii) practice-specific typologies that attempt to describe knowledge types specific to a particular domain e.g. NPD. The focus of this research is to develop a practice-specific knowledge typology for NPD. In the rest of this section an overview will be given of the literature on generic knowledge typologies and practice-specific knowledge typologies.

III(a) GENERIC KNOWLEDGE TYPOLOGIES

Generic knowledge typologies attempt to identify different types of knowledge that are relevant to a broad range of domains. There are two perspectives on generic knowledge topologies. Firstly, there is a viewpoint that suggests that knowledge is a "state or fact of knowing" [11] with knowing being a condition of understanding gained through experience or study; the sum or range of what has been perceived, discovered, or learned. This view of knowledge stresses that knowledge is a cognitive state and does not lend itself readily to mechanization since it encapsulates the set of insights, experiences, and procedures that are considered correct and true and that therefore guide the thoughts, behaviors, and communications of people [12]. From this perspective, knowledge is seen as an object with three dimensions, (i) knowing which, why and when information is needed, (ii) knowing how information is processed, and (iii) knowing where information can be found.

Secondly, there is an alternative viewpoint that sees knowledge as dynamic and ephemeral. "Knowledge is not a thing, or a system, but an ephemeral, active process of relating" [13]. In the same vein Snowdon emphasizes the need to move from a perspective of knowledge as a thing to the view of managing knowledge as a flow. To do this, the focus needs to shift to context and narrative, rather than on content $[14](p .5)$.

Each perspective is summarized in described in Table II (adapted from [15]).

TABLE II: GENERIC KNOWLEDGE TYPOLOGIES

\begin{tabular}{ll}
\hline Cognitive State & Dynamic, Ephemeral \\
\hline Static & Interactive, dynamic \\
\hline $\begin{array}{l}\text { Independent of the } \\
\text { individual }\end{array}$ & $\begin{array}{l}\text { Dependent on the } \\
\text { individual }\end{array}$ \\
\hline Explicit & Tacit \\
\hline Easy to duplicate & $\begin{array}{l}\text { Must be re-created if it } \\
\text { is to be used }\end{array}$ \\
\hline Easy to broadcast & Difficult to transfer \\
\hline Content & Narrative \\
\hline
\end{tabular}




\section{III(b) PRACTICE-BASED KNOWLEDGE TYPOLOGIES}

The linking of knowledge to practice has been a source of interest for researchers for a long time. Epistêmê is the Greek word most often translated as knowledge, while techne is translated as either craft or art. It is in Aristotle that the basis for the modern distinction between epistêmê as pure theory and technê as practice is to be found [16].

Teigland's synthesis of research concerned with the relationship between knowledge and action [17]- and more specifically, between knowledge and action in the workplace, emphasizes the collective, situated, and provisional nature of knowledge in contrast to the rational/cognitive view of knowledge [18]. Out of this body of research come concepts such as "knowledge-in practice" [19], "knowing in practice" [20] and "epistemology of practice" [21].

Lave and Wenger are concerned with "situated learning" and see knowledge as taking the form of historical acquisition of artefacts, whether those artefacts are physical, linguistic or symbolic. "Conventional explanations view learning as a process by which a learner internalises the knowledge, whether "discovered," "transmitted" from others, or "experienced in interaction" with others." [22] (p.47).

The importance of context is also highlighted in the literature on organizational memory. Stein and Zwass identify two types of organizational memories - semantic memory and episodic memory. Semantic memory refers to general, explicit and articulated knowledge. Episodic memory refers to context-specific and situated knowledge. Such memory may be seen as "stored information from an organization's history that can be brought to bear on present decisions" [23]. Context is important because "causal inferences about the behavior of human beings are more likely to be valid when the people in question participate in building and testing them" [24] (p.613).

Nonaka and Konno see knowledge as being embedded in $b a$ (shared places), where it is then acquired through one's own experience or reflections on the experiences of others [25]. Snowdon describes a somewhat similar concept that he calls "cynefin". It is a Welsh word that represents the link between a community and its shared history "in a way that paradoxically both limits the perception of that community while enabling an instinctive and intuitive ability to adopt to conditions of profound uncertainty" [14] (p.10).

The central theme of this approach to knowledge typology is that knowledge is rooted in actions, experience, and is dependant on a specific practice. It is created by and inherent in collective actions of a group based on insights gained from completed projects. In her summary of the literature in this area Teigland points out that Dewey's claim that knowledge is not in what you claim to understand, but what you can do [26]. Bourdieu's seminal contribution developed the concept of practice implying the actions of individuals and groups when conducting real work [27]. There has been some attention by researchers to the categorization of the types of knowledge used in practice in NPD organizations. Table III lists the main contributors and their categorization of NPD knowledge types.

TABLE III: PRACTICE-BASED KNOWLEDGE TYPOLOGIES FOR NPD PROCESSES

\begin{tabular}{ll}
\hline Researcher & NPD Knowledge Type \\
\hline Eder [12] & $\begin{array}{l}\text { Prescriptive (know-how), Descriptive } \\
\text { (know-that) }\end{array}$ \\
\hline Markus [13] & $\begin{array}{l}\text { Shared work producers, shared work } \\
\text { practitioners, expertise-seeking } \\
\text { novices; knowledge producers. }\end{array}$ \\
\hline Nonaka [14] & $\begin{array}{l}\text { Explicit and Tacit with four } \\
\text { knowledge conversion processes: } \\
\text { socialization, externalization, } \\
\text { combination and internalization. }\end{array}$ \\
\hline Nunamaker[28] & $\begin{array}{l}\text { Conceptual framework, System } \\
\text { architecture, System design, System } \\
\text { prototype, System evaluation }\end{array}$ \\
\hline Orlikowski [15] & $\begin{array}{l}\text { Knowing the organization, Knowing } \\
\text { the players in the game, Knowing } \\
\text { how to coordinate across time and } \\
\text { space, Knowing how to develop } \\
\text { capabilities, Knowing how to } \\
\text { innovate }\end{array}$ \\
\hline Rogers [29] & $\begin{array}{l}\text { Tacit, Explicit, Operative, } \\
\text { Substantive, Heuristic, Algorithmic, } \\
\text { Deep, Shallow }\end{array}$ \\
\hline Ullman [30] & $\begin{array}{l}\text { Pre-project, product and process } \\
\text { design, manufacturing }\end{array}$ \\
\hline
\end{tabular}

There is also a growing body of research that sees peer reviews as knowledge-sharing events. Geibler describes some guidelines for the sharing of knowledge in organizations in [31]. He identifies four types of environments for knowledge sharing. One of those models, which he terms the "Discourse Model", has a dual goal of both arriving at an objective truth and achieving consensus about the value of that truth. Peer reviews are a mechanism some companies use to try to arrive at this consensus. Berquist, Ljungberg et al., describe peer reviews as "more or less formalized systems for knowledge sharing and for qualifying new facts and ideas as knowledge" [31]. Frese and Theuven draw attention to the importance of "the degree of sensitivity of interest" as a factor in knowledge sharing [32]. The authors describe the two extremes of this sensitivity as being (a) a high degree of sensitivity of interest where a proactive management of potential conflict is needed and (b) low degree of sensitivity of interest where there is no likelihood of conflict of interest. 


\section{A NEW KNOWLEDGE TYPOLOGY FOR NPD ENGINEERING PROCESES}

The literature summarized in section III indicates a growing body of research in the area of practice-based knowledge typologies for NPD and a realization that peer reviews are in integral part of knowledge creation. Given this body of literature, the stage-gate process in company "A" was subjected to a rigorous analysis to see what types of knowledge were associated with each stage.

Company " $A$ " had already implemented a stage-gate product development process where "gates" are treated as peer reviews where projects undergo a thorough examination and after which executive management decides whether to incur more R\&D expense or not. NPD teams complete a prescribed set of related crossfunctional tasks in each stage before obtaining management approval to proceed to the next stage of product development.

The stage gates were Business Review, Feasibility, Implementation, Validation and Launch. The identification of the critical knowledge used at each stage was done by combining knowledge of the literature summarized in section III and practical experience of running NPD processes in an industrial setting in "A". It is clear that there are different types of knowledge required at different stages of the development process. It is also evident that when considering a KMS to address the NPD process, one needs to consider providing a system that can cater for knowledge that may take different forms. In company " $A$ " there was a concerted effort to exploit the stage gates in the product development process as "formalized systems for knowledge sharing and for qualifying new facts and ideas as knowledge" [38].

A team was formed (with this researcher as leader) with the goal of "defining structures and procedures for technical new product peer reviews that promote knowledge sharing". Initially the focus of the team was on peer reviews that are held early in the product development cycle. The rationale was that improvements to the quality of peer reviews early in the development cycle would yield more substantial results than focusing on reviews later in the cycle because decisions made early in the project have more far-reaching implications than decisions made late in cycle. The peer review in question is called a product architecture review.

Initially the team set about defining the types of products that should be subject to the new peer review process. There were also discussions with leaders in the engineering community on what the expectations of the technical community might be with respect to attendance at such reviews - the content, the number of reviews to be attended by each engineer, etc. This study yielded the following knowledge types at each stage gate:

\begin{tabular}{lll}
\hline \multicolumn{2}{c}{ Stage Gate } & Engineering Knowledge Type \\
\hline 1. & Business Review & 1.Shallow \\
\hline 2. & Feasibility & 2. Fundamental Principles \\
\hline 3. & Implementation & 3. Operative \\
\hline 4. & Validation & 4.Procedural \\
\hline 5. & Launch & 5.Causal \\
\hline
\end{tabular}

These knowledge types can be described as follows: 1. Shallow: At this early stage of the project the primary concern is with market opportunities and how the company's competences might be harnessed to meet a potential customer need. The critical discussions are around understanding the nature of the problem giving rise to the market opportunity. The engineering knowledge being used in these discussion is somewhat "shallow" in that, at this stage, a relatively cursory technical analysis is done. The analysis lacks technical depth but is sufficient to give confidence that the broad technical challenges are not insurmountable and that the technical community have a sound competence in the general area. An awareness of technical achievements in the general domain is very important in this phase.

2. Fundamental Principles: At the feasibility stage of the project the key technical staff display a solid grasp of the fundamental engineering principles that are key to the successful execution of the project. They have an appreciation for the principal engineering challenges and understand the underlying theoretical concepts and practical implications of the task. At this stage the discussions centre around structural and integration issues at a relatively high level of abstraction.

3. Operative: At the implementation stage the primary concern is with actualizing the detailed design. It requires knowledge about how to execute the nitty-gritty aspects of the design and resolve engineering problems at the most specific levels of granularity. Discussions are dominated by issues relating to achieving detailed performance against a very broad and deep range of product specifications. Where possible, knowledge of the operation of previous implementations is leveraged - so as to maximize the benefits of previous experience and thereby reduce risk.

4. Procedural: When the product is at the stage where it is ready to be manufactured attention turns to how to develop a process for the reliable, repeatable development of the product in a manner that maximizes predictability and minimizes variability. Discussions are dominated by concern for routinization and repeatability. Doctrinaire approaches to implementation are often sought and valued.

5. Causal: Subsequent to product launch there is motivation to explore causative aspects of product performance in the market place. Analyses are done that 
try to unearth the underlying reasons for this performance, particularly where there is significant deviation from expected behavior. Any unconventional, unprecedented, or unusual characteristics are isolated for further exploration and analysis.

\section{CONCLUSIONS}

The goal of the research was to develop a knowledge typology for NPD engineering processes that is based on the knowledge shared - in practice - at the stage-gates in company " $\mathrm{A}$ ". The research builds on the practice-based approach to knowledge typologies described above and takes the perspective that stage-gates are a form of peer review or knowledge-sharing event that legitimizes new knowledge.

This research contributes to our understanding of the nature of that knowledge. The different types of knowledge required at different stages of the development process were described and elaborated on. The resulting typology was used to guide the development knowledge management systems to support the NPD process.

\section{REFERENCES}

1. livari, J. and H. Linger. Knowledge Work as Collaborative Work: A Situated Activity Theory View. in Proceedings of the 32nd Hawaii International Conference on System Sciences. 1999. Hawaii, U.S.A.

2. Porter, M. What is Strategy ? in Irish Management Centre Seminar on Innovation. 2003. Dublin, October 9th, 2003.

3. Prahalad, C.K. and G. Hamel, The Core Competence of the Corporation. Harvard Business Review, May-June, 1990. 79-91.

4. Grant, R., Shifts in the World Economy: The Drivers of Knowledge Management, in Knowledge Horizons: The Present and the Promise of Knowledge Management, C. Despres and D. Chauvel, Editors. 2000, Butterworth-Heinemann: Boston. p. 27-55.

5. Cooper, R.G., Developing New Products On Time, In Time. Product Innovation Management, 1994. 11(5).

6. Adler, P.S., et al., Getting the Most Out of Your Product Development Process, in Harvard Business Review. 1996. p. 134. 152.

7. Scott, J.E. The Role of Information Technology in Organizational Knowledge Creation for New Product Development. in Second Americas Conference on Information Systems. 1996.

8. Yang, J. and L. Yu, Electronic New Product Development - a conceptual framework. Industrial Management and Data Systems, 2002. 4(102): p. 218-225.

9. Lewin, K., Frontiers in Group Dynamics. Human Relations, 1947. 1(1).

10. Susman, G.I. and R.D. Evered, An Assessment of the Scientific Merits of Action Research, in Administrative Science Quarterly. 1978. p. 582-603.

11. Spek Van der, R. and A. Spijkervet, Knowledge Management: Dealing Intelligently with Knowledge, in Knowledge Management and Its Integrative Elements, L.a. Wilcox, Editor. 1997, CRC Press: 1997.

12. Schubert, P., D. Lincke, and B. Schmidt. A Global Knowledge Medium as a Virtual Community: The NetAcademy Concept. in Proceedings of the Americas Conference of AIS. 1998.

13. Stacy, R., Complex Responsive Processes in Organizations: Learning and Knowledge Creation. 2001, London, U.K.: Routledge.

14. Snowdon, D., Complex Acts of Knowing: Paradox and Descriptive Self-Awareness. Journal of Knowledge Management, 2000. Spring 2002.
15. Sveiby, K.E., The New Organisational Wealth: Managing and Measuring Intabgible Assets. 1997, San Francisco: Berret-Koehler.

16. Parry, R., ed. Episteme and Techne. The Stanford Encyclopedia of Philosophy, ed. E.Z. Zalta. 2003.

17. Teigland, R., Knowledge Networking. PhD Thesis. 2003 , Stockholm School of Economics: Stockhom.

18. Sole, D. and A. Edmondson, Situated knowledge and learning in dispersed teams. British Journal of Management, 2002. 13(S17S34.).

19. Carlile, P.R., Understanding Knowledge Transformation in Product Development: Making Knowledge Manifest through Boundary Objects. Ph.D Dissertation. 1997, University of Michigan.

20. Orlikowski, W.J., Knowing in Practice: Enacting a Collective Capability in Distributed Organizing. Organization Science, 2000. 13(3): p. 249-273.

21. Cook, S.D.N. and J.S. Brown, Bridging epistemologies: The generative dance between organizational knowledge and organizational knowing. Organization Science, 1999. 10(4): p. 381400.

22. Lave, J. and E. Wenger, Situated learning: Legitimate peripheral participation. 1991, Cambridge: Cambridge University Press.

23. Walsh, J.P. and G.R. Ungson, Organisational Memory. Academy of Management Review, 1991. 16(1): p. 57-91.

24. Argyris, C. and D. Schon, Participatory action research and action science compared. American Behavioural Scientist, 1989. 32(5).

25. Nonaka, I. and $\mathrm{N}$. Konno, The Concept of "Ba"; Building a Foundation for Knowledge Creation. California Management Review, 1998. 40(3): p. 40-53.

26. Dewey, J., The Quest for Certainty, 1929, New York: Capricorn Books.

27. Bourdieu, P., Outline of a Theory of Practice. 1977, Cambridge Cambridge University Press.

28. Nunamaker, J.F., M. Chen, and T.D.M. Purdin, System development in information systems research. Journal of Management Information Systems, 1991. 7(3): p. 99-106.

29. Rodgers, P. and P. Clarkson, An Investigation and Review of the Knowledge Needs of Designers in SMEs. The Design Journal, 1998. 1(3): p. 16-29.

30. Ullman, D.G., The Mechanical Design Process. 1992, New York: McGraw-Hill.

31. Geibler, H., Standardisieriung und Entstandardisierung von Wissen als Aufgabe von Wissenensmanagement, in Projektgruppe wissenschaftliche Bertaung. 1999, Organisationslernen durch Wissenmanagment: Frankfurt/Main. p. 39-63. 